\title{
Full-scale measurements for evaluation of coal dust release from train wagons with two different shelter covers
}

\author{
A.D. Ferreira ${ }^{\mathrm{a}, *}$, D.X. Viegas ${ }^{\mathrm{a}}$, A.C.M. Sousa ${ }^{\mathrm{b}}$ \\ ${ }^{a}$ Department of Mechanical Engineering, University of Coimbra, Polo II, Coimbra 3030-290, Portugal \\ ${ }^{\mathrm{b}}$ Department of Mechanical Engineering, University of New Brunswick, P.O. Box 4400, Fredericton, \\ $N B$, Canada, E3B $5 A 3$
}

\begin{abstract}
The paper describes a full-scale study performed to evaluate the amount of coal dust released by eolian erosion from partly covered train wagons over runs of $350 \mathrm{~km}$. The experimental setup designed for this study is described along with the effectiveness assessment of two types of dust collectors. Airflow statistics are reported for the region immediately above the top level of the wagons. Visualisation tests for the fugitive dust indicate that most of it leaves each wagon primarily through the rear end. The releases from the partly covered wagons are compared against those from the uncovered wagons, to assess the performance of the covers in what concerns the reduction of fugitive dust. The amounts of dust collected after being treated through an error analysis yields an estimate for the total amount of coal released from each wagon under consideration.

The uncertainties resulting from a full-scale study based on actual operating conditions were taken into account and the major contribution of this study is toward the quantification of the fugitive dust release, which seems to have been overlooked in studies appearing in the open literature. The value of less than $0.001 \%$ of the 60 tons net load of coal for partly covered wagons, using a $95 \%$ confidence interval, over a particular $350 \mathrm{~km}$ run, may be representative of many other similar situations. This value tends to be lower than the values usually quoted in different contexts, and primarily within environmental impact assessments.
\end{abstract}

(C) 2003 Elsevier Ltd. All rights reserved.

Keywords: Coal dust; Pollution; Coal train transport; Eolian erosion

*Corresponding author. Tel.: +351-239-790-727; fax: +351-239-790-771.

E-mail address: almerindo.ferreira@dem.uc.pt (A.D. Ferreira). 


\section{Introduction}

A considerable number of studies has been devoted to the environmental impact resulting from the use of coal. Most of these studies, however, have a different scope, e.g., extraction, treatment, and transfer systems [1], storage [2], and combustion and consequent pollution issues $[3,4]$.

Concerning the specific topic of train transportation of coal, the literature is very sparse, and moreover, the references available offer little background information on the numbers for the dust releases used in environmental impact analyses for different energy production scenarios (e.g. [5]). In [4] "fugitive" dust emissions are estimated to lie in the range from $0.05 \%$ and $1 \%$ of the load, however no reference is made to eventual measures to control the dust release, and even more relevant, no source references for the figures are given. The problem of "fugitive" dust reduction using sprays for dust suppressants was analysed in [6]. For a specific railroad, losses in the range of $0-0.3 \%$ are reported in [5], being mentioned a lost of 0.27 tonnes from each rail car during a $960 \mathrm{~km}$ trip $(281 \mathrm{~g} / \mathrm{km} /$ car $)$. No specific details concerning the evaluation and/or measurement method are given.

The problem of "fugitive" dust strongly depends on the wind flow characteristics, as observed in specific wind tunnel studies conducted for coal piles [7]. In these studies, often, only pressure and skin friction distributions are measured on the surface of models used to evaluate dust releases from coal stockpiles $[2,7,8]$.

An extensive literature search conducted by the authors reveals that there is an apparent lack of reliable quantitative information based on studies involving fullscale, or even small-scale, studies devoted to the problem of "fugitive" dust releases during the process of long-distance transportation using train wagons.

The main objective of the present paper is to report on full-scale measurements performed during $350 \mathrm{~km}$-runs from the loading port to the coal stockyard of a two $220 \mathrm{MW}$ coal-burning units power station. The measurements were conducted during the summer months, when the most favourable conditions for the production of dusts are met due to the high temperatures and low level of moisture. This project was conducted in co-operation with Tejo Energia, the company that owns and runs the power station consuming 1.5 million tons of coal per year. The research project also covers work in progress dealing with wind tunnel experiments and numerical modelling.

\section{Experimental setup and procedure}

For the evaluation of the coal dust released during the entire run $(350 \mathrm{~km})$ by the actual train wagons, special dust collectors were specifically designed for this project and they were installed in several wagons. Fig. 1 shows a schematic drawing from a typical wagon, which has the approximate dimensions of $17 \mathrm{~m}$ long, $3.3 \mathrm{~m}$ width and $4 \mathrm{~m}$ height.

The instrumented wagons have two different types of top shelter covers. From the group of four wagons selected, three of them are equipped with two $0.50 \mathrm{~m}$ wide 

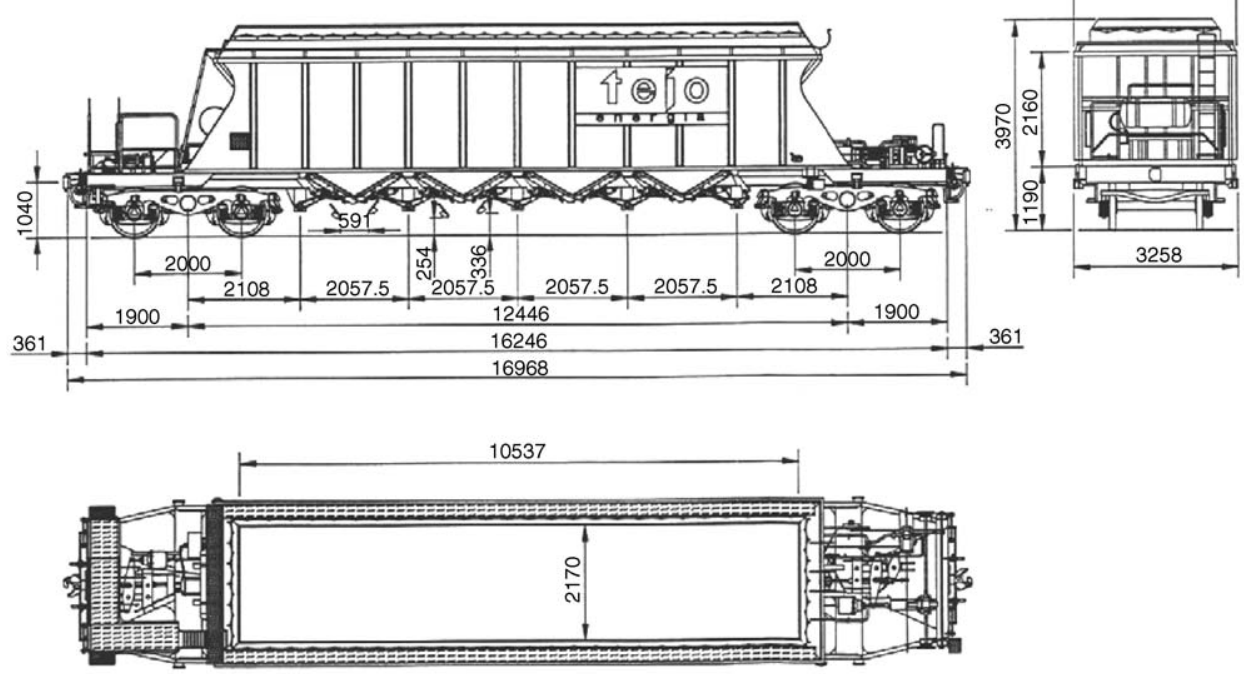

Fig. 1. Front, left and upper views from a typical train wagon used for coal transportation (dimensions in $\mathrm{mm}$ ).

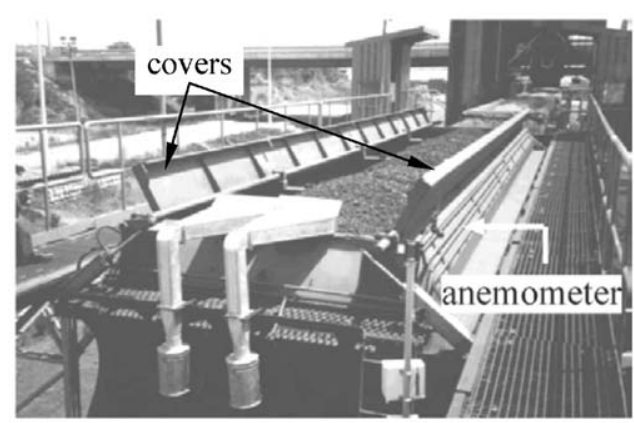

(a)

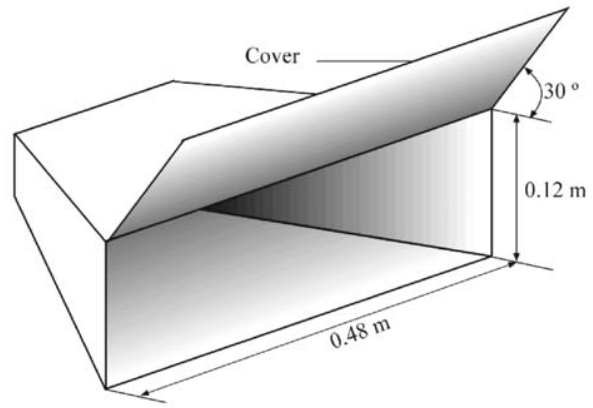

(b)

Fig. 2. View of dust collectors installed on a semi-covered type wagon with the covers open (a); and schematic representation of the upper part nozzle of a dust collector (b).

automatic covers, being hereafter designated as "semi-covered wagons", which have an open gap of $1 \mathrm{~m}$ after they are in the run position (Fig. 2a). The fourth wagon, with an upper opening of $10.5 \mathrm{~m} \times 2.17 \mathrm{~m}$ as shown in Fig. 1, during the transportation was completely covered with canvas manually installed during the first set of experiments and then uncovered for the second set. It should be mentioned that the use of fully covered wagons using automatic shelters is not being considered due primarily to safety issues and coal-handling equipment capacity.

All the dust collectors used in the four equipped wagons are of the same design, for the sake of comparison. The geometry of the upper part is shown in Fig. 2b. Each 
wagon was equipped with a pair of dust collectors, as shown in Fig. 2a, where the "semi-covers" are in the "open" position. During the train run, the "semi-covers" are in the horizontal "closed" position, in contact or near the coal bed.

The lower part of each dust collector consists of a cylindrical container, where dust filters, previously weighted, were installed at the very beginning of the train run. At the end of the run, the weight of each filter was recorded, and qualitative analyses of the coal dust sample were conducted.

The gap between the load device and the upper part of the wagons is quite narrow, usually less than $0.15 \mathrm{~m}$. This limitation imposed strong restrictions on the design of the upper section of the collectors. Therefore, the height of the nozzle was set at $0.12 \mathrm{~m}$, however, to increase the capture area of the nozzle, and also to protect the filters prior to the test runs and during loading and unloading operations, the entrance of the nozzle was equipped with a rotating cover. After the loading of the wagons, the cover was raised, forming a $30^{\circ}$ angle with the horizontal plane as shown in Fig. 2(b), being closed just before the unloading operation at the power plant.

The tests using this type of collectors were carried out for 16 days, in two different series, the first one in July and the second one in September. The first ten testing days (first series) correspond to typical summer days, while the remaining six experiments (numbered from 11 to 16 - during the first days of September) were performed during slightly cooler days and higher relative humidity $(\mathrm{H})$ levels. According with the typical weather conditions of Portugal, the daily amplitude of temperatures is higher in September than in July, with cooler temperatures during the night and approximately the same maximum during the day. Also, in September, during the night and early morning is quite common a high level of humidity yielding high fog conditions. Often the maximum daily temperature in September is very similar to those of the high-summer, as shown in Fig. 3.

Fig. 3 reports the maximum and minimum values for temperature and humidity, respectively, registered at the power plant site for each test day. It should be

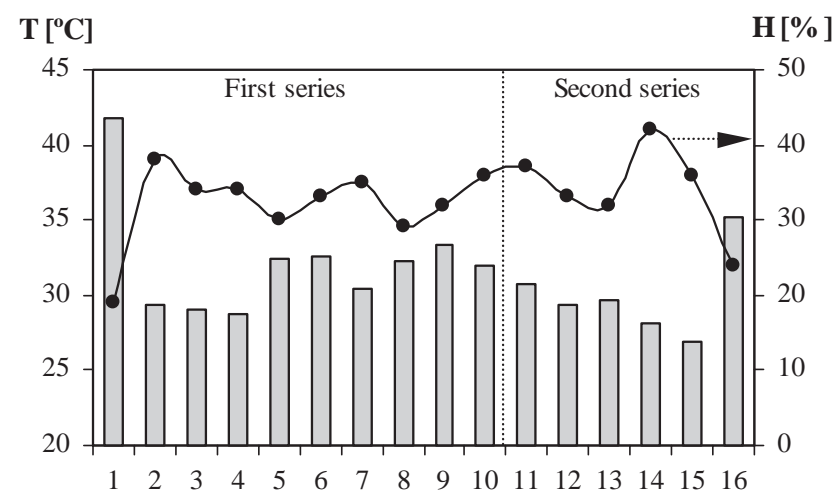

Fig. 3. Maximum daily temperature (T-bars) and minimum daily relative humidity (H-black dots) values for each testing day, measured at the power plant, during the experimental periods. 
mentioned that a small amount $(0.1 \mathrm{~mm})$ of precipitation was observed at the end of the trip (power plant) on test days 14 and 15, while for all the remaining days no significant precipitation was observed.

Usually the instrumented train started its run around 11:30 a.m., and the trip to the power plant was normally $13 \mathrm{~h}$ long, including stops, arriving at the power plant around 0:30 a.m. This train time schedule was selected based on those values of temperature and relative humidity, which were eventually more favourable to the production of dust.

The company Tejo Energia, during the summer, runs four trains per day, each one with 25 wagons and a net load of approximately 1500 tons of coal. During the first $150 \mathrm{kms}$ of the route three diesel locomotives were used to pull the wagons, being replaced by two electrical locomotives for the remaining $200 \mathrm{kms}$. Along the route stops did occur, some of them lasting several hours.

Despite the best attempts made in the beginning, the location on the composition of the different instrumented wagons was not maintained during the entire experimental period. Table 1 shows the location on the train composition, without counting the locomotives, of the diverse pairs of dust collectors. White cells indicate that there is no information for the specific day and pair, because either the filters were not installed or because that particular wagon was not running on that specific day. The wagon with the collectors [C,D] was not used during the second period, which explains the lack of information for that pair.

The wagon with the canvas, where the pair $[\mathrm{G}, \mathrm{H}]$ was installed, travelled always uncovered during the second series period (testing day 11-16). On test day 10, due to operational difficulties, the composition had just two locomotives and 15 wagons.

For the mean flow characterisation at the upper part of the wagons, namely velocity magnitude and direction (relative to the train), a cup-type anemometer and a

Table 1

Position of dust collectors and dust samples available for the different testing days

\begin{tabular}{|c|c|c|c|c|}
\hline \multirow[t]{2}{*}{ Testing day } & \multicolumn{4}{|c|}{ Pairs of collectors } \\
\hline & {$[\mathrm{A}, \mathrm{B}]$} & {$[\mathrm{C}, \mathrm{D}]$} & {$[\mathrm{E}, \mathrm{F}]$} & {$[\mathrm{G}, \mathrm{H}]$} \\
\hline & & & & Covered \\
\hline $1-6$ & $1 \mathrm{st}$ & 13 th & 24 th & 25 th \\
\hline 7 & $1 \mathrm{st}$ & 13 th & 17 th & 18 th \\
\hline 8 & $1 \mathrm{st}$ & 13 th & 17 th & \\
\hline 9 & $1 \mathrm{st}$ & 7 th & & \\
\hline \multirow[t]{2}{*}{10} & & 9 th & & \\
\hline & & & & Uncovered \\
\hline 11 & $3 \mathrm{rd}$ & & 4 th & 2nd \\
\hline 12 & $3 r d$ & & 4 th & 2nd \\
\hline 13 & $3 r d$ & & & 2nd \\
\hline 14 & $3 r d$ & & & $2 \mathrm{nd}$ \\
\hline 15 & $3 r d$ & & 4 th & 2 nd \\
\hline 16 & & & & 2nd \\
\hline
\end{tabular}


flow-direction sensor were mounted slightly above the wagons' top level, at the rear part of one of the instrumented wagons, between two consecutive wagons, as shown in Fig. 2b. As the anemometer and direction sensor are attached to the train, during its movement, the flow velocity registered is an added contribution from the train velocity plus the wind flow in each location. Therefore, the flow is characterised in relation to a referential fixed to the wagon. The North $(\mathrm{N})$ direction was assumed for flows blowing parallel to the wagon's longitudinal axis, from the front to the rear. This means that any direction other than $\mathrm{N}$ is indicated just if there is a cross wind sufficiently significant comparatively to the train speed.

The placement of this instrumentation was strongly limited by operational conditions, in particular safety issues, such as proximity to high voltage power lines, overpasses, bridges and tunnels.

Due to the location of the flow sensors, specifically the proximity of the sensors to the wagon, it is expected that the measurements performed were influenced by the wagons and structures located upstream. Even so, since the flow erosion occurs through the top gap, the recorded information for the flow velocity and direction, near the top, is very important for the characterisation of some parameters influencing the erosion process.

For a better characterisation and understanding of the flow along the upper part of the wagons, a video camera was mounted for a few train runs to record the behaviour of long light strips specifically used for flow visualisation purposes. This strips, one with a quarter of the wagon's length, one-half and two with the full length, were made of plastic with a width of $0.07 \mathrm{~m}$ and very thin, having a weight of $1.75 \mathrm{~g} / \mathrm{m}$.

To accomplish a more complete analysis further information about the flow would be needed, namely distributions of turbulence intensity and shear stress near the coal free surface, very important parameters for the study of small particles transportation physics. Such experiments, however, could not be conducted due to restrictions imposed by safety regulations and operational conditions. For example, in some of the experiments performed, namely flow visualisations and the use of a large filter, as mentioned in Section 3, the time available for the installation of the equipment, performed after the load operation, was very short, only a few minutes, as the trains' schedules remained unchanged.

\section{Results}

\subsection{Air flow statistics}

The physics of small exposed particles to wind, such as blown sand, depends on the flow characteristics, as explained in [9] - a classic reference in this field. In fact, this type of erosion depends on the wind speed, velocity profile, turbulence intensity, shear stress at the surface level, just to mention some of the flow characteristics involved. Therefore, it is important to have some information of the air flow at the wagon's top level. 


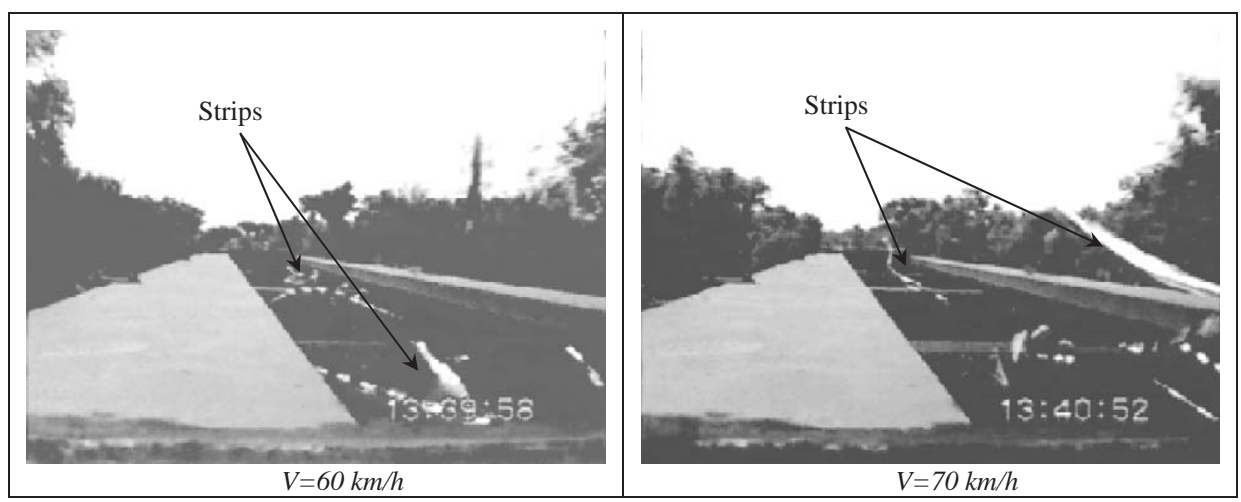

Fig. 4. Flow visualisation using strips recorded during the train movement ( $V=$ train velocity).

Fig. 4 shows the strips' behaviour (visible in white colour along the gap) in two typical recorded images at different train speeds. From the observations two main features can be noted: (1) the turbulent behaviour of the flow mainly aligned with the wagon; (2) the longest strips, with the length of the top part of a wagon $(10.5 \mathrm{~m}$ long), had a few times their trailing edges lifted $0.1-0.2 \mathrm{~m}$ above the small dust collectors.

Concerning the first feature, one can conclude that the flow over the wagons' top, despite its high turbulence level, is mainly aligned with the longitudinal axis of the wagon. This is apparent in Fig. 4 for the longest strips $(10.5 \mathrm{~m} \mathrm{long})$, where it is clearly shown that most of the fugitive dust leaves the wagon by its rear end, the dust escaping sideways being negligible.

Short strips were also used $(2 \mathrm{~m}$ long) to visualise the flow features on the region of the wagon's front. Their behaviour confirmed the existence of a recirculation zone around the front region of the wagon, as it can be seen by the lifting of the short ribbon on the right picture of Fig. 4. It should be mentioned that the loading operation of any wagon starts at its rear end and, as noticed, the height of stacked coal is higher at the rear than at the front. Therefore, as expected, the strongest source of fugitive dust is located close to the rear part where the dust collectors were installed. Observation at close proximity, using the video camera, do not reveal noticeable releases from the front end of the wagon, a region where it was apparent that considerable amounts of fine dust particles remained at the end of the runs.

The second observation lends some support to the assertion in what concerns the releases through the wagons' sides, which may be considered negligible, as compared to the total amount of fugitive dust produced. Also, it may lead to the conclusion that a certain fraction of the dust may go over the nozzle entrance, and the collectors will not capture it. This suggests that tests using larger collectors may help to quantify the uncertainty in what concerns the total amount of dust released. This particular analysis will be covered in Section 3.3.

In addition to the flow visualisation tests, 1 min-averages, as well the maximum flow speed for each time interval, during some train runs were recorded on a data 
Table 2

Flow-direction frequency as a function of the air speed recorded by the anemometer mounted on a train wagon

\begin{tabular}{lccccc}
\hline Air velocity $(\mathrm{km} / \mathrm{h})$ & {$[0-20]$} & ] $20-40]$ & ] $40-60]$ & ] $60-80]$ & Total $(\%)$ \\
\hline $\mathrm{N}$ & 12.4 & 18.2 & 42.1 & 6.6 & 79.3 \\
$\mathrm{NE}$ & 0.0 & 0.0 & 0.0 & 0.0 & 0.0 \\
$\mathrm{E}$ & 0.0 & 0.0 & 0.0 & 0.0 & 0.0 \\
$\mathrm{SE}$ & 0.0 & 0.0 & 0.0 & 0.0 & 0.0 \\
$\mathrm{~S}$ & 8.3 & 0.8 & 0.0 & 0.0 & 9.1 \\
$\mathrm{SW}$ & 10.7 & 0.0 & 0.0 & 0.0 & 10.7 \\
$\mathrm{~W}$ & 0.0 & 0.0 & 0.0 & 0.0 & 0.0 \\
$\mathrm{NW}$ & 0.0 & 0.0 & 0.8 & 0.0 & 0.8 \\
{$[\%]$} & 31.4 & 19.0 & 43.0 & 6.6 & $100 \%$ \\
\hline
\end{tabular}

logger. Table 2 reports on a statistical data treatment presenting the flow-direction frequency as a function of the flow-speed. From it one can conclude that the prevailing direction coincides with the train orientation, here taken as North $(\mathrm{N})$, in agreement with the visualisation experiments. This observation supports, along with the visualisation tests performed with the strips, the choice for the placement of dust collectors only at the rear end of the wagons.

Table 2 shows also that just for the lowest flow velocity level, some flow-directions other than $\mathrm{N}$ were recorded, these being observed mainly during train stop periods. During those periods the flow velocity measured is due only to the wind. From this table one can verify that, for travel velocities higher than $20 \mathrm{~km} / \mathrm{h}$, the mean flow blows along the wagon for more than $98 \%$ of the time.

Fig. 5 shows the flow-velocity measured by the cups-anemometer during one portion of a typical train run. Two long stops can be clearly identified, the first between $0 \mathrm{~h} 40 \mathrm{~min}$ and $1 \mathrm{~h} 00 \mathrm{~min}$ and the second one from $3 \mathrm{~h} 20 \mathrm{~min}$ to $4 \mathrm{~h} 00 \mathrm{~min}$, time measured from the begin of the train movement at the port. The first part of the trip, from the begin until $3 \mathrm{~h} 20 \mathrm{~min}$, corresponds to the segment of the run where the diesel locomotives are used, being characterised by lower velocities, with a maximum of $65 \mathrm{~km} / \mathrm{h}$, while during the second one a maximum velocity of $85 \mathrm{~km} / \mathrm{h}$ was observed.

\subsection{Coal dust collected}

The coal has a typical particle size distribution under oven-dried conditions of: retained in $50 \mathrm{~mm}$ round screen $2.8 \%$, and in $6.3 \mathrm{~mm} 53.8 \%$, and passing $6.3 \mathrm{~mm}$ $43.4 \%$, and for the evaluation of the amount of coal dust released during each run, two procedures were used. The first was based on the use of the dust collectors already described, while the second one employs a larger collector. This procedure and the data analysis are to be discussed in Section 3.3. This section only addresses the coal captured by the small collectors.

As mentioned before, the tests were conducted with each wagon equipped with a pair of dust collectors, from now on referred as pairs $[A, B],[C, D],[E, F]-$ for the 


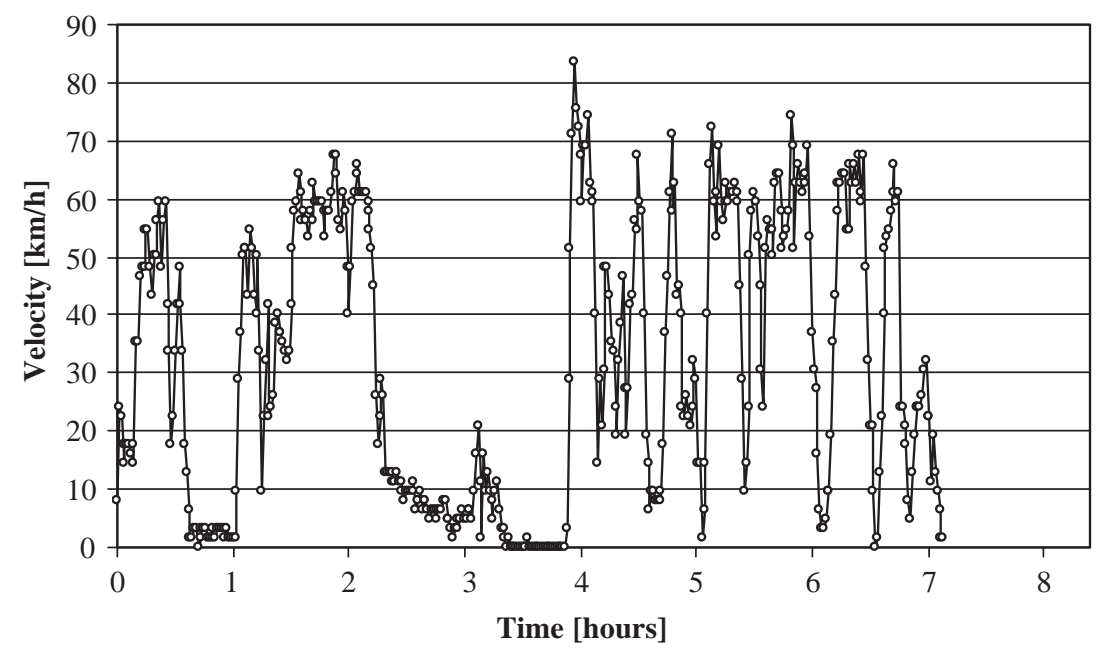

Fig. 5. Average air velocity registered by the anemometer mounted on a train wagon, during one portion of a typical run (1 min-averaged values).

semi-covered wagons, and $[\mathrm{G}, \mathrm{H}]$ for the wagon protected with canvas during part of the tests.

Fig. 6 shows the amount of coal acquired in each pair, during the 16 different testing days. From these results it can be noticed that the samples for testing day number 5 are considerably larger than all the other ones for the remaining days. For this specific test, no particular experimental difficulties were reported, therefore no obvious explanation can be found for this discrepancy. The results from this particular test, despite being included in the statistic analysis discussed later on, should be considered with some caution.

For the pair $[\mathrm{G}, \mathrm{H}]$, installed in a wagon that was covered with canvas during the first series as mentioned before, the amount collected is very small as compared to that for the wagons equipped with "semi-covers", as expected. In fact, aside of test day number 5 , the dust collected is practically negligible. For the test days number 6 and 7, just some large pieces of coal weighing several grams, therefore with zerolikelihood to be carried by the flow at such low velocities, were found inside of filter G, but no dust. During the second series this specific wagon was uncovered (Table 1), with the upper gap $2.2 \mathrm{~m}$ wide (Fig. 1), and consequently, the captured amount of release is considerably larger than those from the first series. Also, as its gap is more than double of the "semi-covered" wagons, the amount of dust captured is considerably larger than the samples of collectors $[\mathrm{A}, \mathrm{B}]$ and $[\mathrm{E}, \mathrm{F}]$, for the same days. This remark suggests that the "semi-covers" produce significant shelter effect against the production of fugitive dust, but additional controlled tests are necessary to quantify this effect.

Considering the less favourable days for dust production (first series), it can be noticed, for all the semi-covered wagons, that typically each pair collects coal samples weighs less than $40 \mathrm{~g}$, as reported in the graph Fig. 7. This graph shows the 

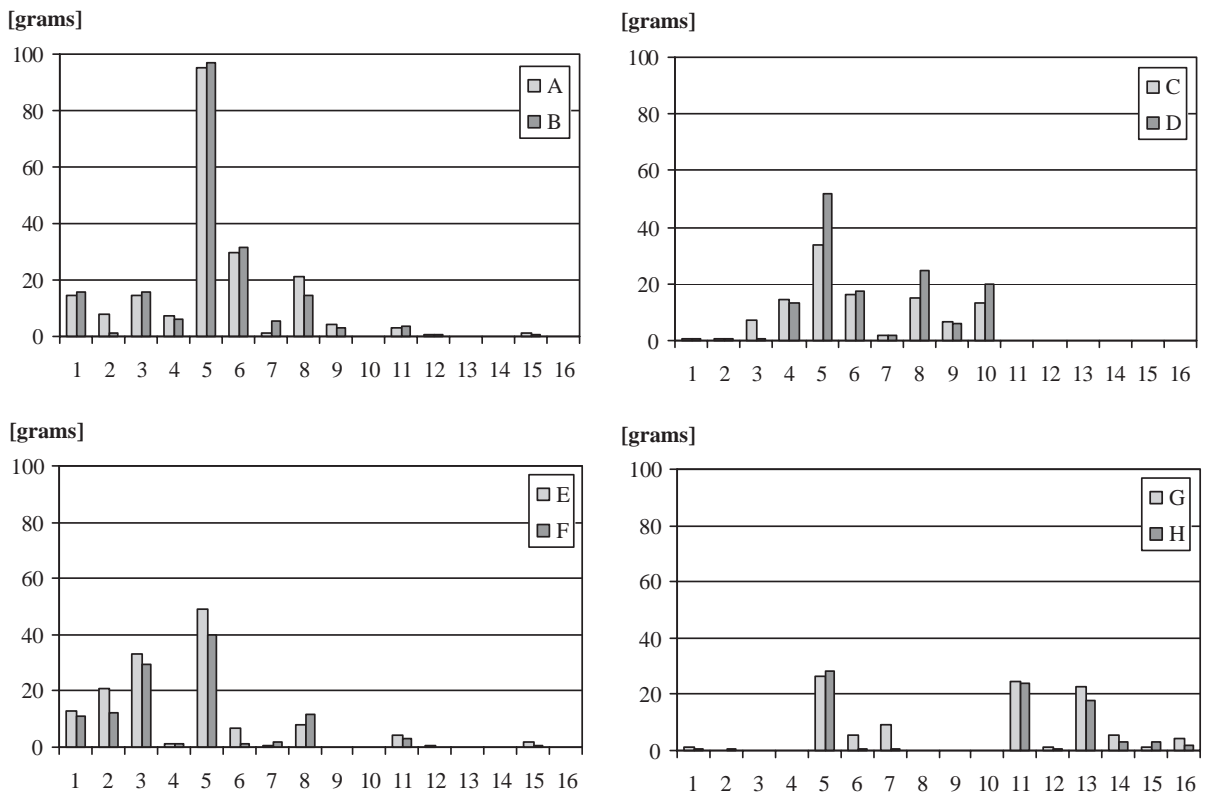

Fig. 6. Coal dust weight captured, in each testing day, by the several pairs of collectors (A-F-semicovered wagons; $[\mathrm{G}, \mathrm{H}]$ open wagon-1-10 testing days: covered, 11-16 testing days: uncovered).

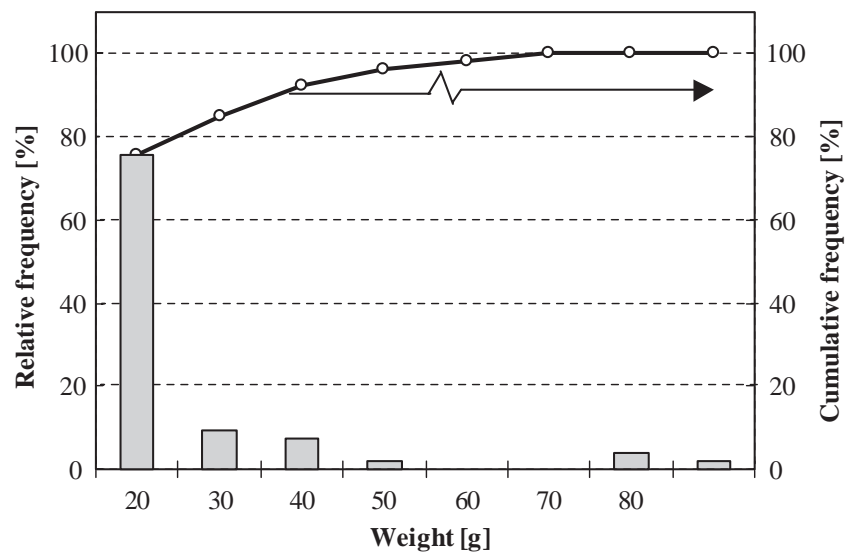

Fig. 7. Relative (bars) and cumulative (dots) frequency distributions, per class of coal dust weight received by each collector and per train run, for the semi-covered wagons and first series values.

relative and cumulative frequency distributions of each weight class of coal received by the different semi-covered wagons' collectors, during all the first series' train runs.

As shown in Fig. 7, 75\% of the samples weigh less than $20 \mathrm{~g}$, approximately $20 \%$ range between 20 and $40 \mathrm{~g}$, and just for the worst case (collectors [A,B], day number 5) are above $80 \mathrm{~g}$. 
Using the data from collectors A to $\mathrm{F}$ and the first 10 samples, a mean value $(\mu)$ of $13 \mathrm{~g}$ is calculated with a standard deviation $(\sigma)$ of $18 \mathrm{~g}$. Assuming that the weight from the samples follow a normal distribution, and considering a $95 \%$ confidence interval, it can be said, based on the experimental data, that each wagon releases less than $100 \mathrm{~g}(2[\mu+2 \sigma])$.

The value of the standard deviation is quite high as an expression of a considerable level of uncertainty in the results. The dust collected is a multi-variable function, depending on the amount and distribution of the load along the wagon, on the particles' size, wind flow, train velocity, just to mention a few. None of these parameters could be controlled in the present full-scale study, so there is good reason to consider potential uncertainties in the data analysis.

\subsection{Error analysis}

As clearly mentioned, the coal loading conditions impose serious size constraints on the dimension of the collectors. The recorded images confirm that, as expected, a fraction of the air flows, eventually carrying coal particles, by-pass the collectors, which may yield higher values for the dust releases than those measured.

In order to evaluate the confidence level of the results previously discussed, one extra test was conducted using a larger filter, made out of cloth with a very fine mesh. This large collector basically consists of a shaped bag, with a nozzle covering all the width of the rear upper part of the wagon, with a capturing area $1.75 \mathrm{~m}$ wide and $0.50 \mathrm{~m}$ high (Fig. 8), i.e., a nozzle with a frontal area 5 times larger than that for the pair of small collectors.

As mentioned before, diesel locomotives were used for the traction of the wagons during the first $150 \mathrm{kms}$. From the visualisation tests, it was observed that the engines' exhaust flows close to the upper surface of the first wagons. To avoid this extra-source of pollution, the large filter was installed approximately in the middle of the train. This fact is responsible for introducing some uncertainty to the results, as some dust might have its origin from wagons placed upstream. However, as this aspect is also common to the other collectors and, as a comparison between the two filter systems is the primary aim, no special measures were taken to correct this
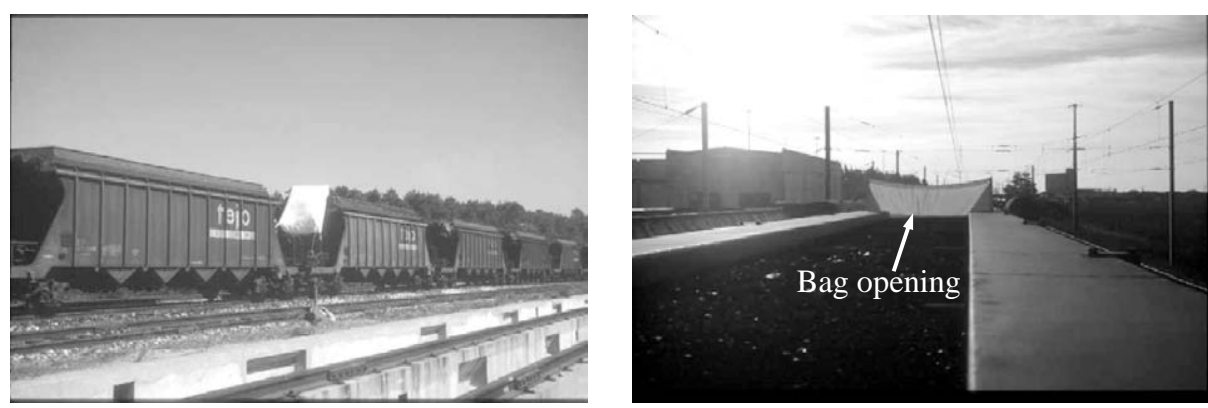

Fig. 8. Rear and front views of the large dust collector installed (left — train in movement; right - train at a stop). 
situation. Also, as the flow is highly turbulent, developed conditions are expected to occur after the flow has passed over the first few wagons.

During this train run, $43 \mathrm{~g}$ were received by a pair of small dust collectors, located several wagons downstream of the large filter. A total of $143.5 \mathrm{~g}$ of coal was received by the large collector, which is 3.3 times more than the amount for the pair of small collectors. If one admits an "integrating factor" of 4 , based on an augmentation of the weights relative to the values just calculated, that takes into account all the uncertainty and limitations described previously in the preceding section as this filter is much larger, a global estimate of $400 \mathrm{~g}$ /wagon $(100 \times 4)$ can be made. Again, using a $95 \%$ confidence interval, it can be said that each semi-covered wagon, during a $350 \mathrm{~km}$ run, releases about $0.001 \%$ of its usual 60 tons coal load (about $1.2 \mathrm{~g} / \mathrm{km} / \mathrm{car}$ ).

This result is considerably smaller than the usual values indicated in the available literature, 50 times less than the lower limit indicated in [4], and much smaller than the " $281 \mathrm{~g} / \mathrm{km} /$ car" mentioned in [5].

\section{Concluding remarks}

A full-scale study was conducted in order to estimate the amount of coal dust released during a $350 \mathrm{~km}$ journey using semi-covered wagons. The work was primarily focused on the air flow characterisation and on the analysis of the samples collected from several dust collectors installed.

The amount of coal dust released from this type of wagons was found to be approximately $0.001 \%$ of its load, a value much smaller than those usually quoted in the literature. The results from a large bag sampler are critical in reaching this specific conclusion.

The apparent discrepancy between the present findings and previously accepted values will be further investigated. A new battery of full-scale measurements is being planned for the summer months, and the pressure drop of the collectors, which was estimated to be between 7 and $10 \mathrm{kPa}$, will be reduced by $30-40 \%$.

From the second series, when the wagon equipped with collectors $[\mathrm{G}, \mathrm{H}]$ travelled with its upper surface unprotected, it was observed that the wagons with "semicovers" released a comparatively smaller amount of dust, suggesting a "protection" effect due to the covers used. Only through controlled laboratory conditions, it will be possible to ascertain about the potential advantages of the semi-covers. Therefore, this full-scale program will be backed up by wind-tunnel experiments in a 1:25 scale and numerical modelling.

\section{Acknowledgements}

This work was funded by FCT (Science and Technology Foundation of Portugal) (Project POCTI/33512/EME/2000) with funds from the European Community through the FEDER Program.

The sustained support received from Tejo Energia, and in particular from its liaison officer, Eng. António Lopes da Silva, and from EMEF Companies is 
acknowledged. The contribution of Mr. António Teles Cardoso toward the experimental tests is most appreciated.

\section{References}

[1] I.H. Knoepfel, A framework for environmental impact assessment of long-distance energy transport systems, Energy 21 (1996) 693-702.

[2] S.-J. Lee, C.-W. Park, The shelter effect of porous wind fences on coal piles in POSCO open storage yard, J. Wind Eng. Ind. Aerodyn. 84 (2000) 101-118.

[3] T.F. Edgar, Coal Processing and Pollution Control, Gulf Publishing company, Houston-Texas, 1983, $579 \mathrm{p}$.

[4] OECD, Coal-Environmental issues, remedies, Organisation for Economic Co-operation and Development (1983) 87p.

[5] J.K. Lazo, K. McClain, Community perceptions, environmental impacts, and energy policy: rail shipment of coal, Energy Policy 24 (1996) 531-540.

[6] R. McClaren, Preventing profits blowing away, Coal Int. 244 (1996) 2.

[7] A.R. Borges, D.X. Viegas, Shelter effect on a row of coal piles to prevent wind erosion, J. Wind Eng. Ind. Aerodyn. 29 (1988) 145-154.

[8] J. Xuan, A. Robins, Effects of turbulence and complex terrain on dust emissions and depositions from coal stockpiles, Atmos. Environ. 28 (1994) 1951-1960.

[9] R.A. Bagnold, The Physics of Blown Sand and Desert Dunes, Methuen \& Co. Ltd, London, 1941. 